\title{
Research and Methodology
}

\section{Motivation and Research Questions}

Having worked as experts in an association of banks for more than a decade, we have gained a deep understanding of the potentials and strengths of this unique institution in the socio-economic system. Thanks to a developed network of international cooperation, we could observe the practices of other associations, which enabled us to have a sort of benchmark that helped us to improve our practice many times in recent history. We have witnessed various phases, activities, project developments, and interactions with other institutions in the country. By being active participants in most of these, we gained an understanding of the scope of the association and the power it does (not) have, which naturally led us to the position where we can apply an analytical view and discover more in-depth possibilities and potentials of its role.

In the past, national banking associations have had their members' interests at the core of their daily and strategic activities. Nowadays, the role and mission of the associations have adapted to the needs of other important stakeholders, too: professionals, financial services users, and the public (society). Furthermore, not only do the national banking associations have more relevant stakeholders to deal with (quantity aspect), but also the impact and activities of the associations have transformed and adapted to the needs of those stakeholders (quality aspect).

In our daily work, working in a banking association, we are witnessing that it is not rare that the mission and existence of the banking association is not familiar enough to the public, users of financial services, and sometimes professionals in other sectors. In relation to this, there are often assumptions, such as: a banking association is a public sector body, a banking association is like a bank, a banking association is a supervisor, a banking association should approve loans. Observing this practice over time resulted in our growing motivation to conduct this kind of research.

In addition, as banking association professionals (specialists), we have been carefully observing constant changes in the environment at various levels: our member banks (technological, organizational, and so on), clients' needs and positions, stakeholders' list and interests, regulators' expectations, and so on, all of them are of an exogenous nature. What about the banking association itself? We have been triggered, therefore, due to the changes in the environment, to analyze the association itself and to discover endogenous factors that banking associations can manage directly to be agile with the requirements of stakeholders. Some of our basic questions in the research are:

- May all those changes affect the association?

- To what extent and in which direction?

- What are the main endogenous aspects that will support such a change: statute, staff, organization, mission, and so on? 
These questions and others are, we hope, answered in the book. Therefore, our main hypotheses in the research are:

- National banking associations, with their mission, purpose, activities, and organization, are a very important pillar of the national financial systems although their purpose and contribution are not sufficiently known to a wider audience (H0).

- Although the national banking associations are traditional business associations, they have various mechanisms to cope actively with changes in the environment (H1).

The objective of the research is very closely linked to the above described position of the banking association today. The general purpose of the analysis is threefold:

1. For the banking industry (professionals) and banking industry representatives (banking associations), by reviewing their current activities and organization and by providing them with a ground for the exchange of best practices that national banking associations could benefit from and exchange among themselves.

2. On the other side, the findings of this research could be used by national regulators, supervisors, governments, and other policy makers.

3. Eventually, scholars, students, teachers of financial literacy, and the public might benefit by improving their understanding of the role of the banking associations, their potential, and programs - particularly given the direct dedication to financial services users (for example, financial education, advice, circumstances related to the Covid-19 pandemic).

The findings of this empirical study have relevant scientific contribution, too. This book will directly contribute to the academic and research activity, knowledge, and data source of scholars active in studying the subjects related to, for example, banking, finance, central banking, contemporary economic systems, the role of institutions in the development, and economic growth. Research findings disclose the role and activities of the banking associations, therefore proving their significant role as important institutions for financial system stability in promoting economic growth and development.

\section{Scope of the Research}

The analysis of the activities of banking associations in Europe includes a total of 70 associations, including representative national banking associations and regional and international banking associations. Representative associations of banks from the following groups of countries were observed: 
1. European banking associations - all national banking associations from:

a. EU member countries - full members of the European Banking Federation (EBF) were analyzed including Western Europe (Austria, France, Italy, Germany, Spain, and so on), Central and Eastern Europe (Bulgaria, Poland, Romania, Slovakia, Czech Republic, and so forth), and some southeast European countries (Greece).

b. Non-EU member countries - national banking associations from Southeast Europe, that is, mostly Western Balkan countries (Serbia, Bosnia and Herzegovina, Montenegro, North Macedonia, Albania) and countries of the Euro Asia region, that is, former Soviet Union countries (Russia, Ukraine, Uzbekistan, Kyrgyzstan, and so on).

2. Worldwide - selected countries from other regions and parts of the world are presented.

3. Regional and international banking associations - due to the importance of international cooperation, several "associations of the associations" are presented, such as the European Banking Federation, the International Banking Association, the Latin American Federation of Banks (FELABAN), the Australian Financial Complaints Authority (AFCA), the Banking Association of Central and Eastern Europe, and the Union of Arab Banks.

The research was conducted from March 2020 to June 2021.

The observed sample is considered as representative, since they are relevant national associations of banks that bring together all banks, or in a small number of cases almost all banks, with an asset share of not less than 90\% (as in the case of Slovakia and the Czech Republic). Russia is a slightly different example due to the fragmented structure of its banking sector.

\section{Methodology}

Many of our research questions have been answered by the findings of several levels of analysis. The methodologies used are determined by the empirical character of the research: statistical method as the general method (limited to the descriptive statistics), in combination with the method of induction, synthesis and analysis methods, methods of generalization, the case study method, and the method of interviews. We have also applied desktop research.

The research was therefore conducted by combining different methods. Part I of the monograph aims to disclose the nature, functioning, structure, and activities of national banking associations. Therefore, we have used direct knowledge of the work of banking associations resulting from direct cooperation with them and within the European Banking Federation (EBF) network, a review of banking statistics issued 
by the EBF, desk research, and direct insight from the website and interviews. Additionally, we have created the survey of the role of banking associations, and we have shared it among European banking associations; therefore, the responses of relevant partners were presented in the book to test/justify/prove/reject additional findings from our previous sources and methods. Also, to test Hypothesis $\mathrm{HO}$ and to answer some research questions, we have developed Appendix I: Register of National Banking Associations to show all national banking associations from Europe, and in addition, from selected countries all over the world covering various geographical regions. The list of national banking associations is expanded by the list of international banking associations for the reason of their importance as platforms for joint representation of national banking sectors at the supranational level. Each national banking association is presented by information categorized in four sections and according to the publicly available data. ${ }^{2}$ The purpose of this analysis and register is to disclose what banking associations are, what their mission is, how their are organized and governed, and what activities and priorities they have today. In this way, we tested Hypothesis Ho.

Following the analysis and findings from Part I, in Part II we test hypothesis H1 by analytically exploring the mechanisms and capabilities of the banking association as the institution to deal with constant changes. Methods of induction and deduction were used, applying theoretical backgrounds (Agenda 2030, and so on) and important market impacts (digitalization, etc.) on the changes of their structure, mission, and activities. Also, by discovering a direct correlation between the size of the association and their orientation/responsiveness to the public and stakeholders (including changes), we have developed the matrix that identifies potential strategic positionings of the associations in a time of change. We considered the nature and origin of these changes and their influence on one side, and the mechanisms of the response to these changes and the impact of the association on the other. In this way we have tested H1, and we proved their adaptability to changes, and their growing importance as institutions in building resilient infrastructure of the national financial systems today.

Part III relies on the Registry of the Banking Associations (from Part I) by adding an additional level of analysis - through case study method and particular analysis of each banking association, analytically observing various approaches to the same goals (and topics) and discovering their similarities and differences. Aside from this thorough analysis of each banking association (70), which we classified into several geographical groups, we have developed an overview of the most relevant national banking associations' activities that have the highest relevance in the organization in terms of their importance and frequency. The analytical approach

2 Publicly available data are taken directly from the official sources - official websites of each national banking association. 
to activities is applied, and they are listed in detail but also grouped (towards their stakeholders). Although the list has been created for the banking associations from Europe $^{3}$ (Western Europe, Central and Eastern Europe, Southeast Europe), the analysis of the most frequent and most important activities can be applied to any other banking association (due to our findings from Chapter 11 on similarities and differences).

In the last part of the book, we have developed a model that indicates the adaptability of banking associations. This model may be considered universal, aimed at assessing and evaluating the effectiveness of each individual association of banks; it is inevitable, however, to consider all the peculiarities and circumstances that may have an impact on this type of assessment. In the recommendations we give, we identify ten fundamental assumptions that need to be considered when evaluating the work of banking associations.

\section{Notes, Remarks, and Challenges during Research}

The data presented in this publication has been compiled from publicly available information published by the official websites of the national banking associations, unless otherwise noted. Most of the associations pay particular attention to certain highly important themes, which stay high positioned on the agenda for many years. These include, for example, the promotion of better EU or national regulation. Occasionally, some topic gains importance for a few months. We have tried to collect them all, however, keeping in mind that we live in a turbulent time with frequent changes and that some of the topics covered in this book may lose their relevance over time after the publishing of this book.

Sources, statements, and quotations from the national banking associations' websites very often are left without extensive comments or explanation. Most of them are self-explanatory and left to the reader for their own assessment.

Examples of associations have been chosen at random for the publication's chapters and sections. Sometimes European banking associations are quoted, while in some other sections former Soviet Union or Far East associations are mentioned as examples. The intention was to have an as wide as possible representation of worldwide associations and to present each banking association (from the sample observed) at least once in various levels of analysis, as a good practice example in a certain area.

3 Both for EU and non-EU members. 
